\title{
Benefits of Exercise Training For Computer-Based Staff: A Meta Analyses
}

\author{
Mothna Mohammed \\ Department of Sport Studies, Faculty of Education, University Putra Malaysia, Malaysia \\ E-mail: alqanas.sport@gmail.com \\ Farah Layth Naji (Corresponding author) \\ Department of Sport Studies, Faculty of Education, University Putra Malaysia, Malaysia \\ E-mail: girlsport969@gmail.com
}

Received: 19-02- 2017

Accepted: 25-04- 2017

Published: 30-04- 2017

doi:10.7575/aiac.ijkss.v.5n.2p.16

URL: http://dx.doi.org/10.7575/aiac.ijkss.v.5n.2p.16

\begin{abstract}
Background: Office workers sit down to work for approximately 8 hours a day and, as a result, many of them do not have enough time for any form of physical exercise. This can lead to musculoskeletal discomforts, especially low back pain and recently, many researchers focused on home/office-based exercise training for prevention/treatment of low back pain among this population. Objective: This Meta analyses paper tried to discuss about the latest suggested exercises for the office workers based on the mechanisms and theories behind low back pain among office workers. Method: In this Meta analyses the author tried to collect relevant papers which were published previously on the subject. Google Scholar, Scopus, and PubMed were used as sources to find the articles. Only articles that were published using the same methodology, including office workers, musculoskeletal discomforts, low back pain, and exercise training keywords, were selected. Studies that failed to report sufficient sample statistics, or lacked a substantial review of past academic scholarship and/or clear methodologies, were excluded. Results: Limited evidence regarding the prevention of, and treatment methods for, musculoskeletal discomfort, especially those in the low back, among office workers, is available. The findings showed that training exercises had a significant effect $(\mathrm{p}<0.05)$ on low back pain discomfort scores and decreased pain levels in response to office-based exercise training. Conclusion: Office-based exercise training can affect pain/discomfort scores among office workers through positive effects on flexibility and strength of muscles. As such, it should be suggested to occupational therapists as a practical way for the treatment/prevention of low back pain among office workers.
\end{abstract}

Keywords: Exercise, low back pain, sedentary lifestyle, therapy

\section{Introduction}

In current decade, absence of physical activity and regular exercise is known as one of the issues among societies and lead to different types of physical, physiological and psychological issues (Beebe \& Harris, 2013). Most of the current researches related to absence of physical activity are mostly done among geriatrics, athletes or children, but there are a few papers about physical activity for different occupations (Koren, Pišot, \& Šimunič, 2016). Low back which distress the spine area, is the greatest frequently described musculoskeletal discomforts (Ivanova et al., 2011). Around $80 \%$ of the individuals is pretentious by it at some point in their lives, with some approximations being high. Low back pain reasons substantial personal sorrow due to pain, disability and reduced quality of work and life in overall, and these can be a countless socioeconomic burden (Sihawong, Janwantanakul, Sitthipornvorakul, \& Pensri, 2011). The low back's exact etiology is not often recognized, primary to regular practice of the diagnostic label "non-specific pain" when no detailed pathologic construction or procedure is identifiable (Gatti et al., 2011). Even though these are usually caring discomforts which often determine within a few weeks, approximately $10 \%$ of the patients grow chronic pain, that not only has a major influence on an their life superiority, but also makes a burden to a society's healthcare scheme while simultaneously lowers output levels and growing work malingering (Jakobsen et al., 2014). The individuals' quantities who are disabled by low back pain are about $11 \%$ to $12 \%$ of the population. Considering an economic standpoint, these kinds of pain have become one of the most financially tedious discomforts which is the result of rising incidence in industrialized countries (Talebian, Hosseini, Bagheri, Olyaei, \& Reazasoltani, 2011). Existing statistics have put the expected straight outlays at about US \$91 billion per year and, on average, individuals with low back pain experience roughly $60 \%$ higher overall healthcare costs than people without pain (Babaei, Rahnama, Nadi, \& Sajjadian, 2013). The greatest regularly used non-pharmacological method to treat/prevent of low back pain is doing regular physical activity (Maher, 2000). Exercise therapy and doing a regular pattern of physical activity such as walking or swimming is usually a real treatment for utmost cases of nonspecific low back pain. Many researches talked about the benefits of regular physical activity on musculoskeletal 
system and specially for the people with non-specific low back pain (Thorp et al., 2012), but the researchers have shown different types of physical activity with different intensity and frequency. The main problem of office workers related to the absence of physical activity is related to their limited time and also the payments for the going to gym or buys the facilities. So, it made the researchers interested to design the home/office-based exercise training for this population. Though, treating individuals with non-specific pain repeatedly shows extra stimulating, in large part due to the extensive variety of possible reasons elaborated (Van Middelkoop et al., 2010). Inappropriately for healthcare professionals, a huge proportion of individuals who hurt from low back pain drop into this class (Sheahan, Diesbourg, \& Fischer, 2016). Extra than $80 \%$ of all patients who protest of low back pain hurt from nonspecific pain, in which no shortest organic signs or instantaneous structural associations to the feelings they knowledge can be seen (McGill, Childs, \& Liebenson, 1999). Inadequate analytical actions may subsidize to the lack of inevitability in low back (Holmström, Lindell, \& Moritz, 1992). Greatest repetition such as physical therapy has been exposed to be actual cooperative in the treatment/prevent of non-specific back pain. In furthermost countries, physiotherapy also contains an wide and individualized exercise package, same as the study done by Sherman et al., 2005). Table 1 shows the list of selected current researches with focus on exercise therapy for low back pain. This table shows the target group and also type of office based exercise training that was used as a treatment.

Table Error! No text of specified style in document.. Past studies on different methods of treatment for musculoskeletal discomfort, especially low back pain

\begin{tabular}{|c|c|c|c|}
\hline Author & Subjects & Issue & Treatment \\
\hline $\begin{array}{l}\text { Robertson } \\
\text { MM, } 2003\end{array}$ & Officers workers & Musculoskeletal discomfort & $\begin{array}{c}\text { Office ergonomics } \\
\text { workplace and training }\end{array}$ \\
\hline $\begin{array}{l}\text { Sherman } \\
\text { KJ, } 2005\end{array}$ & 101 adults & Chronic low back pain & $\begin{array}{c}\text { Yoga or conventional } \\
\text { therapeutic exercise classes } \\
\text { or a self-care }\end{array}$ \\
\hline $\begin{array}{l}\text { Robertson } \\
\text { M, } 2009\end{array}$ & 96 office workers & $\begin{array}{l}\text { Musculoskeletal } \\
\text { Disorders }\end{array}$ & Office ergonomics training \\
\hline $\begin{array}{l}\text { Sherman } \\
\text { KJ, } 2011\end{array}$ & 228 adults & $\begin{array}{c}\text { Chronic low back, neck and } \\
\text { shoulder pain }\end{array}$ & Yoga and stretching \\
\hline $\begin{array}{l}\text { Irmak A, } \\
2012\end{array}$ & 39 healthy office workers & Musculoskeletal pain & $\begin{array}{c}\text { Exercise reminder software } \\
\text { programs }\end{array}$ \\
\hline $\begin{array}{l}\text { Del Pozo- } \\
\text { Cruz B, } \\
2012\end{array}$ & 100 office workers & Sub-acute low back pain & $\begin{array}{c}\text { Web-based } \\
\text { multidisciplinary } \\
\text { intervention and standard } \\
\text { care }\end{array}$ \\
\hline $\begin{array}{l}\text { Lomond } \\
\mathrm{KV}, 2014\end{array}$ & $\begin{array}{l}58 \text { subjects with chronic, } \\
\text { recurrent low back, neck } \\
\text { and shoulder pain }\end{array}$ & low back, neck and shoulder pain & $\begin{array}{l}\text { Trunk stabilization vs. } \\
\text { general strength and } \\
\text { conditioning exercises }\end{array}$ \\
\hline $\begin{array}{l}\text { Sihawong } \\
\mathrm{R}, 2014\end{array}$ & 563 office workers & Low back, neck and shoulder pain & $\begin{array}{l}\text { Exercise program consisting } \\
\text { of muscle stretching and } \\
\text { endurance training }\end{array}$ \\
\hline $\begin{array}{l}\text { Shariat et } \\
\text { al, } 2016\end{array}$ & 40 office workers & $\begin{array}{l}\text { Musculoskeletal discomforts with } \\
\text { focus on low back pain }\end{array}$ & $\begin{array}{l}\text { Exercise training of muscle } \\
\text { stretching }\end{array}$ \\
\hline $\begin{array}{l}\text { Dalager et } \\
\text { al., } 2016\end{array}$ & 390 Danish office workers & Low back pain & $\begin{array}{l}\text { Intelligent physical exercise } \\
\text { training }\end{array}$ \\
\hline
\end{tabular}

Robertson et al., posited that a sequence of office-based exercise training would be integral in the lowering of physical pain among office workers (Robertson \& O’Neill, 2003), Robertson et al., showed that ergonomic modifications will exhibit identical results on pain levels (Robertson et al., 2009), and subsequently in 2011, Sherman et al, introduced Yoga as a practical form of treatment for office workers to decrease the severity of pain in their backs (Sherman et al., 2011). In 2012, Irmak et al., suggested a software program that notifies office workers about their physical exercise routines (Irmak \& Irmak, 2012) and, at the same time, Del Pozo et al., mentioned that dependence on exercise training alone will not be effective, because office workers need special care as well (PozoCruz et al., 2012). Similarly, in 2014, Lomond et al., compared Trunk stabilization vs. general strength and conditioning exercises in response to low back pain among office workers (Lomond, Henry, Hitt, DeSarno, \& Bunn, 
2014). That same year, Sihawong published the results of his longitudinal study and showed the positive effects of office-based exercise training on musculoskeletal discomforts, especially on low back pain among office workers (Sihawong, Janwantanakul, \& Jiamjarasrangsi, 2014). In 2016, there were two important researches in this area. At first, Shariat el al., showed the positive effect of 11 week-long office-based exercise training, with focus on low back pain among office workers in Malaysia (Shariat, Lam, Kargarfard, \& Danaee, 2015), followed by Dalager et al., in a longitudinal study among 390 Danish office workers, who revealed that not all forms of exercise training can affect the score of pain in the low back (Dalager, Justesen, Murray, \& Sjøgaard, 2016). Dalager et al., also introduced intelligent physical exercise training with high intensity for the treatment of low back pain among office workers. Indeed, the findings of Dalager et al., support the findings of Shariat et al., and addressed the lacuna present in the latter, where the duration of treatment is concerned. Thus, the positive effects of exercise training for reducing pain/discomfort in the low back are already known, but there is a lacuna in identifying a specific package of exercise training for office workers who do not have sufficient time to work out at the gym and lack the required exercise facilities in the workplace (Thorp et al., 2012). Also, there is no specific source to collect the different types of suggested exercise training by the researchers that can reduce low back pain among office workers. As such, the main purpose of this Meta analyses was to discuss about the mechanisms and theories behind low back pain and subsequently suggest suitable packages of exercise training for office workers to curb this problem.

\section{Methods}

This Meta analyses paper analyzed the recent applicable available papers linked to musculoskeletal discomforts with focus of non-pharmacological therapy for low back pain and summarized those that are easy and practical to be done by office workers, in office setting. PubMed, Scopus, and Google Scholar from 2003 to 2016 were the sources for findings the articles. Office workers, musculoskeletal discomforts, low back pain, and exercise training were the used keyword for search. Among our 4 selected key words (office workers, musculoskeletal discomforts, low back pain, and exercise training), only office worker was not available in Mesh source. Based on a research by Richter, not all the scientific terms are available in MeSH source, and some of those need to be entered into the MeSH database (Richter \& Austin, 2012). Only the articles that were published with same methodology were selected. Among 41 papers, those with clear methodology and same subjects, with an office-based exercise training treatment were selected, and studies that failed to report sufficient sample statistics, or did not have a deep review on literature, or did not have a clear methodology, were excluded. Among 41 papers, 10 papers with clear methodology and same subjects, with an office-based exercise training treatment were selected (Figure 1). Base on Chambers' (2004) study, systematic reviewers usually eliminate a great proportion of researches - at times $90 \%$ or more. Researches are normally left out from the pool of researches since they (a) obviously meet one or more of the exclusion criteria, (b) contain ambiguous or incomplete methods, (c) cannot meet a predetermined threshold for quality, or (d) fail to report adequate data or statistics to estimate effect sizes (Chambers, 2004).

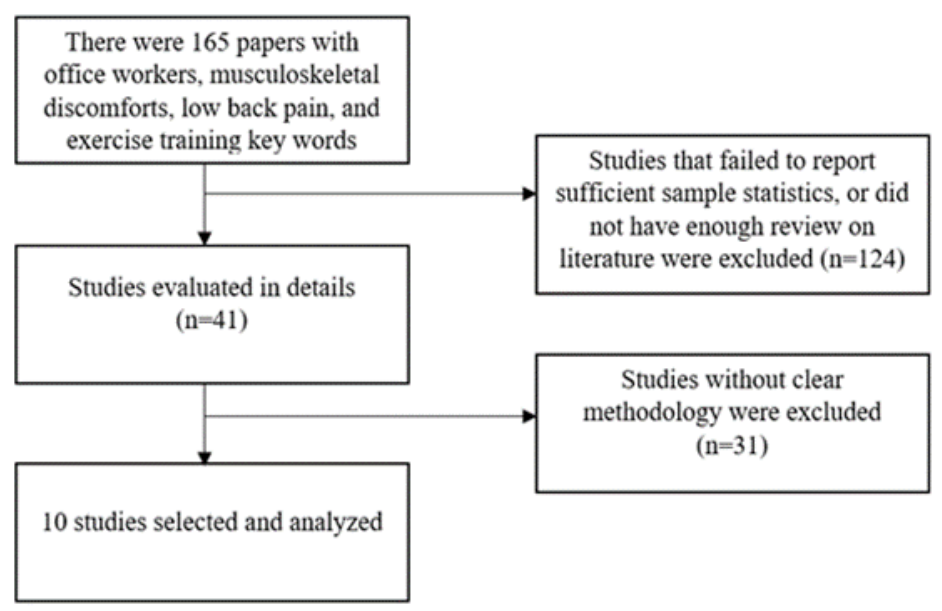

Figure 1. Selection of papers based on criteria

\section{Results}

The electronic database search identified 165 records after removal of duplicates. After screening by title and abstract, full articles were then obtained for 10 trials and their eligibility assessed against the inclusion criteria (Figure 1). Based on the finding of selected papers, it is necessary to talk about the anatomy and theories behind low back pain as the readers can understand the related mechanism and after it, it is easier to digest their findings.

Thirty three vertebrae create the backbone and fibro-cartilaginous discs are in between, which perform as cushions and aid the double purpose of avoiding inter-vertebral friction and at the same time protects the spinal cord. the spinal cord and nerves are connected via a some gaps between the vertebrae, which provides sensations and messages to the skin and muscles (Mak et al., 2010). A person's intervertebral disc includes a gelatinous core that is 
enclosed with a circle of fibrous material. Regarding its normal condition, most of the disc is not linked to either the nervous system or circulatory directly, as it is made of particular cells which are able to persist deprived of a direct blood source (Pronk, Katz, Lowry, \& Payfer, 2012). Gradually, the discs' flexibility lost and become less capable of absorbing the physical stress. So the ability is reduced more stress is created to other spine parts, that leads to the spine's ligaments thickening and as a result the bony growths grow on the vertebrae, causing little space over which nerve roots and the spinal cord can pass. The findings of previous studies (Fairbank et al., 2011; Henschke et al., 2010) confirmed that, long term sitting and absence of regular physical activity is the main reason for decreasing the flexibility of discs and have a negative effect on absorbing the physical stress among office workers. Once a disease or injury results in disc degeneration, its structure also changes: herniated disc material might push onto a nerve root directly, any of which alterations may result in back pain. A simple low back pain among office workers can be known as a small injury, but in long time can be changed to a series disease results in disc degeneration among office workers (Dalager, Justesen, \& Sjøgaard, 2015). Muscles and ligaments of the abdomen and back are responsible for the steadiness to the spine, whereas a collection of tiny joints known as facet joints control the spine motion whereas restraining its range (Baumgartner et al., 2012). The multifidus muscles are a group of muscles that are referred to as run along the back of the spine, and provide extra steadiness and ensure that the spine remains straight through many normal actions such as lifting, walking and sitting (Figure 3). These are normally injured in individuals who are suffering from chronic back pain, since the primary pain regularly results in the individual to improperly use the back muscles when trying to escape the pain. The difficulty with the multifidus muscles usually remains even after the initial pain is resolved, and is a probable reason of frequent pain (Mörl \& Bradl, 2013). So, it can be concluded that the type and category of back pain would be related to the job task, and based on the nature of task in office workers, their back pain will be recognized as a chronic back pain. Generally, an uncomfortable feeling is called pain which to the reaction of an incident which might injure or hypothetically harm the body tissues. There are four key phases in the process of pain sensation: transduction, transmission, perception and modulation (Hayes et al., 2012; Jensen \& Karoly, 1991). Some stimulus activate the nerve cells - thermal, mechanical or chemical, these contain cell bodies which are located in the sensory fibers and dorsal root ganglia that transfer signals to the spinal cord. When an event that causes the pain-causing stimuluses the right sensory nerve endings of the cells the process of pain feeling starts, and about the office workers, the stimulation is mechanical (Nadler, Malanga, DePrince, Stitik, \& Feinberg, 2000). This kind of cell can transform the incident into an electrical signal as a result of Transduction. Great number of different kinds of nerve fibers transfer the electrical signal from the transducing cell to the spinal cord's posterior horn, from there to the brain stem, and then from the brain stem to different parts of the brain including the thalamus and the limbic system (Grahek \& Dennett, 2011; Lamm, Decety, $\&$ Singer, 2011). The pain signals are managed by the brain and increases the sensation of the pain. Using neuroplasticity and modulation, the transmitting further nerve impulses may be revised by brain with increase or reduction in the neurotransmitters discharge which are dealing with pathways sensory and are ascending it (Grahek \& Dennett, 2011). The pain signals can bother office workers and effect their social and private life, and it will have a negative effect on their efficiency during working hours (Lombardi, Folkard, Willetts, \& Smith, 2010) . A systematical study was done by Linton and van Tulder in 27 controlled trials found that there were sufficient evidence which reveals that in the general population back pain is efficiently avoided by exercise therapy, also it was discovered that decrease in the severity of the pain and musculoskeletal discomfort score in a targeted area can be reduced by exercise therapy (Linton \& van Tulder, 2001). Non-specific pain in the back region in different careers is not probable to initiate from similar cause because patients are vulnerable to different danger elements. Accordingly, application of similar exercise regimen for everybody that suffer back pain cannot be reasonable. Typically, office work contains long working period with a computer. As suggested by some evidences continued mouse and computer use can cause tension back syndrome that is the common diagnosis in the back area of computer users and is associated with pain severity and high scores of musculoskeletal discomfort. Nowadays, it is still unclear which kind of exercise is appropriate for office employees (Sihawong et al., 2011), and likewise which kind of exercise might affect the scores of musculoskeletal discomfort. Back pain, that regularly causes reduced negative mood changes and physical activity, may in fact result in a decline in fitness or be observed as such (Heyward \& Gibson, 2014). The low back pain effect on physical activity is not completely clear, despite the fact fitness and health are commonly supposed to affect the occurrence of low back pain (Helmhout et al., 2010). It is also stated that greater scores of musculoskeletal discomfort and lower ranges of motion occur among people with low back pain. An earlier research (Mayer, Mooney, \& Dagenais, 2012) has revealed that exercise offers many advantages for all those people with low back pain, and positive influences in them concerning stress, feelings and depressive, and anxiety disorder. Also exercise could to reduce the pain severity and scores of musculoskeletal discomfort (Sihawong et al., 2011). So far, most of the researches, reported about the positive influences of exercise training, such as aerobic exercise, strength training, various types of meditation and yoga (Babaei, Rahnama, Nadi, \& Sajjadian, 2013). Some of the latest studies including the research conducted by Shariat et al., presents a particular exercise training package for office employees, focusing on low back area (Siegmund, Barkley, Knapp, \& Peer, 2014). The most recent and accurate research with a clear methodology and clear findings was belonged to Dalager et al., among Danish office workers, and they introduced intelligent physical exercise training with high intensity, for treatment of low back pain among office workers (Dalager et al., 2015). They also, mentioned about the mechanisms and theories behind the effect of exercise training on low back pain. The main differences between the study done by Shariat et al. (2016), and Dalager et al. (2016), was related to the duration of intervention. It 
should be noted that, Shariat el at., reported their results based on the severity of pain, but Dalager et al, showed their findings based on the total score of pain.

\section{Discussion}

Low back pain is not a particular illness by itself, but is instead a series of signs which might be interpreted as the result of a range of probable fundamental problems, with some being more serious than others. At present, no one seems to have a clear or single reason. Rather, it is supposed that the problem is due to skeletal or muscular problems including strains or sprains, regularly complicated by other aspects. Issues such as stress, rapid weight gain (especially due to pregnancy), obesity, poor overall physical fitness, smoking, awkward positioning and the adoption of poor posture while sleeping have been identified as some of the main culprits (Center, Relief, Covington, \& Parr, 2012).

This paper focused on 10 researches with clear methodology, because in some of the research the package of exercise, intensity and frequency of that program was not mentioned clearly (Dalager et al., 2016; del Pozo-Cruz et al., 2013; Irmak \& Irmak, 2012; Lomond et al., 2014; Robertson, Ciriello, \& Garabet, 2013; Robertson \& O’Neill, 2003; Sherman et al., 2011, 2005; Sihawong et al., 2014). The suggested programs had same target but the designs were different. Doing the regular daily Yoga, ergonomic training, and stretching exercises were the suggested programs. The researchers controlled and reminded the exercises in different ways such as calling or reminding by a software. These researches have also mentioned that low back pain is manifested in the event when movements with elements of bending forward, or twisting, are carried out. This means that office workers usually sense such pain after working hours (Sihawong et al., 2011). The onset of the symptoms might happen soon afterwards, or soreness may emerge the next morning upon waking up. Normally the description of symptoms varies from tenderness at a specific point to a more diffusive pain across the entire lower back. Often it will worsen with specific movements, including raising a hand or leg, or when the body is in specific positions, including standing or sitting, although this might not constantly be the case. This researches use different tests such as measuring the range of motion, evaluation the level of pain by questionnaire or using EMG. Their measurements were repeated one or two times after baseline and it was also compared with a control group. Problem in bringing the leg and low range of motion in hip joint was recognized as a symptom for low back pain, and in some cases the person was known as a patient with Sciatica - a condition of physical pain radiating down the legs. The first experience of low back pain usually occurs between the ages of 20 and 40 years, and this kind of pain persists among a sizable percentage of people, and recurring spells tend to be more painful compared to the initial bout (Henschke et al., 2010). Most of the office workers are normally 20 to 40 years old and prone to back pain. Other issues might also surface in combination with this kind of pain. Sleep disorders, to begin with, are quite common, and may include difficulties in falling asleep, along with problems while sleeping, less restful sleep, and shorter sleep duration, especially among office workers with different shifts (Esquirola, 2011), and this can affect their performance during working hours and also will have a negative impact on their social and private life (Biglarian et al., 2012).

Most office workers who suffer from prolonged low back pain also start to show signs of mental discomfort, including anxiety or depression (Balagué, Mannion, Pellisé, \& Cedraschi, 2012). Earlier research have revealed that walking during a short break decreases their discomfort (Healy et al., 2013), and other studies have highlighted the advantageous influences of stretching exercises pain for 6-8 weeks on such pain (Sherman et al., 2011). These findings show the positive influence of physical activity on the reduction of pain (Coggon et al., 2013; Lambeek, van Mechelen, Knol, Loisel, \& Anema, 2010). It is accepted that the total advantages of flexibility are to be seen in biomechanical (Siegmund et al., 2014), neurological (Sullivan, Scheman, Venesy, \& Davin, 2012) and molecular systems (Neufer et al., 2015), that comprise myofibrillogenesis as a long-term consequence. It might also be considered that enhancements in overall flexibility can increase tolerance to soreness as well as visco-elastic properties in the tendons and muscles (McCaskey, Schuster-Amft, Wirth, Suica, \& de Bruin, 2014) .When dealing with muscle conditioning, 36-48 hours of relaxation between exercises is suggested, and it is also recommended to increase the intensity of exercise training during that time (Dalager et al., 2015). In addition, because flexibility workouts modify muscle proteins, excessive catabolism will be avoided by a similar relaxation period between exercise sessions (Van Middelkoop et al., 2010). The theory underlying the value of stretching exercises, particularly for back muscles, is connected to muscle tightness. Both prolonged sitting and lack of physical movement will result in muscle tightness, since such muscles as quadriceps, gluteus, hamstrings, multifidus and the erector spine are not subjected to sufficient physical activity and are instead retained in a particular position for a long period of time. As a result, the range of motion in related joints, such as the hips, will also be reduced, and this will subsequently lead to low back pain.

\section{Conclusion}

Most researches have been conducted in the US and Europe and there is an absence of knowledge concerning a connection between occupational therapy and exercise science especially among Asian. It is also essential to associate occupational health and exercise science concerning physical movement, and give information to office employees who are improbable to accomplish physical movement in their spare time. The effectiveness of exercisebased treatment and occupational treatment and their simultaneous influences require to be studied. 


\section{References}

Babaei, M., Rahnama, N., Nadi, M. A., \& Sajjadian, P. (2013). The effect of exercise therapy and ergonomic based on virtual space in computer users with low back pain. Journal of Research in Rehabilitation Sciences, 9(1), 104112.

Balagué, F., Mannion, A. F., Pellisé, F., \& Cedraschi, C. (2012). Non-specific low back pain. The Lancet, 379(9814), 482-491.

Baumgartner, D., Zemp, R., List, R., Stoop, M., Naxera, J., Elsig, J. P., \& Lorenzetti, S. (2012). The spinal curvature of three different sitting positions analysed in an open MRI scanner. The Scientific World Journal, 2012.

Beebe, L. H., \& Harris, R. F. (2013). Description of physical activity in outpatients with schizophrenia spectrum disorders. International Journal of Mental Health Nursing.

Biglarian, A., Seifi, B., Bakhshi, E., Mohammad, K., Rahgozar, M., Karimlou, M., \& Serahati, S. (2012). Low back pain prevalence and associated factors in Iranian population: findings from the national health survey. Pain Research and Treatment, 653060. http://doi.org/10.1155/2012/653060

Center, C., Relief, P., Covington, L. A., \& Parr, A. T. (2012). Caudal epidural injections in the management of chronic low back pain: A systematic appraisal of the literature. Pain Physician, 15, E159-E198.

Chambers, E. A. (2004). An introduction to meta-analysis with articles from the journal of educational research (1992-2002). The Journal of Educational Research, 98(1), 35-45.

Coggon, D., Ntani, G., Palmer, K. T., Felli, V. E., Harari, R., Barrero, L. H., ... Serra, C. (2013). Disabling musculoskeletal pain in working populations: Is it the job, the person, or the culture? PAIN®, 154(6), 856-863.

Dalager, T., Justesen, J. B., Murray, M., \& Sjøgaard, G. (2016). Prevalence of low-back pain in Danish office workers and the effect of Intelligent Physical Exercise Training. In 9th International Scientific Conference on the Prevention of Work-Related Musculoskeletal Disorders.

Dalager, T., Justesen, J. B., \& Sjøgaard, G. (2015). Intelligent Physical Exercise Training proves effective in enhancing muscle strength and reducing musculoskeletal pain in a workplace setting. In ECSS.

del Pozo-Cruz, B., Gusi, N., del Pozo-Cruz, J., Adsuar, J. C., Hernandez-Mocholí, M., \& Parraca, J. A. (2013). Clinical effects of a nine-month web-based intervention in subacute non-specific low back pain patients: a randomized controlled trial. Clinical Rehabilitation, 27(1), 28-39.

Esquirola, Y. (2011). Shift work and cardiovascular risk factors: New knowledge from the past decade. Archives of Cardiovascular Disease, 104, 636-668.

Fairbank, J., Gwilym, S. E., France, J. C., Daffner, S. D., Dettori, J., Hermsmeyer, J., \& Andersson, G. (2011). The role of classification of chronic low back pain. Spine, 36, S19-S42.

Gatti, R., Faccendini, S., Tettamanti, A., Barbero, M., Balestri, A., \& Calori, G. (2011). Efficacy of trunk balance exercises for individuals with chronic low back pain: a randomized clinical trial. Journal of Orthopaedic \& Sports Physical Therapy, 41(8), 542-552.

Grahek, N., \& Dennett, D. C. (2011). Feeling pain and being in pain. mit Press.

Hayes, S. C., Bissett, R. T., Korn, Z., Zettle, R. D., Rosenfarb, I. S., Cooper, L. D., \& Grundt, A. M. (2012). The impact of acceptance versus control rationales on pain tolerance. The Psychological Record, 49(1), 3.

Healy, G. N., Eakin, E. G., LaMontagne, A. D., Owen, N., Winkler, E. A. H., Wiesner, G., ... Fjeldsoe, B. S. (2013). Reducing sitting time in office workers: short-term efficacy of a multicomponent intervention. Preventive Medicine, 57(1), 43-48.

Helmhout, P. H., Staal, J. B., Heymans, M. W., Harts, C. C., Hendriks, E. J. M., \& de Bie, R. A. (2010). Prognostic factors for perceived recovery or functional improvement in non-specific low back pain: secondary analyses of three randomized clinical trials. European Spine Journal, 19(4), 650-659.

Henschke, N., Ostelo, R. W., van Tulder, M. W., Vlaeyen, J. W., Morley, S., Assendelft, W. J., \& Main, C. J. (2010). Behavioural treatment for chronic low-back pain. Cochrane Database Syst Rev, 7(7).

Heyward, V. H., \& Gibson, A. (2014). Advanced fitness assessment and exercise prescription 7th edition. Human kinetics.

Holmström, E. B., Lindell, J., \& Moritz, U. (1992). Low Back and Neck/Shoulder Pain in Construction Workers: Occupational Workload and Psychosocial Risk Factors. Spine, 17(6), 663-671.

Irmak, A., \& Irmak, R. (2012). The effects of exercise reminder software program on office workers' perceived pain level, work performance and quality of life. Work, 41(Supplement 1), 5692-5695.

Ivanova, J. I., Birnbaum, H. G., Schiller, M., Kantor, E., Johnstone, B. M., \& Swindle, R. W. (2011). Real-world practice patterns, health-care utilization, and costs in patients with low back pain: the long road to guidelineconcordant care. The Spine Journal, 11(7), 622-632. 
Jakobsen, M. D., Sundstrup, E., Brandt, M., Kristensen, A. Z., Jay, K., Stelter, R., ... Andersen, L. L. (2014). Effect of workplace-versus home-based physical exercise on pain in healthcare workers: study protocol for a single blinded cluster randomized controlled trial. BMC Musculoskeletal Disorders, 15(1), 119.

Jensen, M. P., \& Karoly, P. (1991). Control beliefs, coping efforts, and adjustment to chronic pain. Journal of Consulting and Clinical Psychology, 59(3), 431.

Koren, K., Pišot, R., \& Šimunič, B. (2016). Active workstation allows office workers to work efficiently while sitting and exercising moderately. Applied Ergonomics, 54, 83-89.

Lambeek, L. C., van Mechelen, W., Knol, D. L., Loisel, P., \& Anema, J. R. (2010). Randomised controlled trial of integrated care to reduce disability from chronic low back pain in working and private life. Bmj, 340.

Lamm, C., Decety, J., \& Singer, T. (2011). Meta-analytic evidence for common and distinct neural networks associated with directly experienced pain and empathy for pain. Neuroimage, 54(3), 2492-2502.

Linton, S. J., \& van Tulder, M. W. (2001). Preventive interventions for back and neck pain problems: what is the evidence? Spine, 26(7), 778-787.

Lombardi, D. A., Folkard, S., Willetts, J. L., \& Smith, G. S. (2010). Daily sleep, weekly working hours, and risk of work-related injury: US National Health Interview Survey (2004-2008). Chronobiology International, 27(5), 10131030 .

Lomond, K. V, Henry, S. M., Hitt, J. R., DeSarno, M. J., \& Bunn, J. Y. (2014). Altered postural responses persist following physical therapy of general versus specific trunk exercises in people with low back pain. Manual Therapy, $19(5), 425-432$.

Maher, C. G. (2000). A systematic review of workplace interventions to prevent low back pain. Australian Journal of Physiotherapy, 46(4), 259-269.

Mak, J. N. F., Hu, Y., Cheng, A. C. S., Kwok, H. Y., Chen, Y. H., \& Luk, K. D. K. (2010). Flexion-relaxation ratio in sitting: application in low back pain rehabilitation. Spine, 35(16), 1532-1538.

Mayer, J., Mooney, V., \& Dagenais, S. (2012). Lumbar Strengthening Exercise. Evidence-Based Management of Low Back Pain, 104.

McCaskey, M. A., Schuster-Amft, C., Wirth, B., Suica, Z., \& de Bruin, E. D. (2014). Effects of proprioceptive exercises on pain and function in chronic neck-and low back pain rehabilitation: a systematic literature review. $B M C$ Musculoskeletal Disorders, 15(1), 1.

McGill, S. M., Childs, A., \& Liebenson, C. (1999). Endurance times for low back stabilization exercises: clinical targets for testing and training from a normal database. Archives of Physical Medicine and Rehabilitation, 80(8), 941-944.

Mörl, F., \& Bradl, I. (2013). Lumbar posture and muscular activity while sitting during office work. Journal of Electromyography and Kinesiology, 23(2), 362-368.

Nadler, S. F., Malanga, G. A., DePrince, M., Stitik, T. P., \& Feinberg, J. H. (2000). The relationship between lower extremity injury, low back pain, and hip muscle strength in male and female collegiate athletes. Clinical Journal of Sport Medicine, 10(2), 89-97.

Neufer, P. D., Bamman, M. M., Muoio, D. M., Bouchard, C., Cooper, D. M., Goodpaster, B. H., ... Mattson, M. P. (2015). Understanding the cellular and molecular mechanisms of physical activity-induced health benefits. Cell Metabolism, 22(1), 4-11.

Pozo-Cruz, B. del, Adsuar, J. C., Parraca, J. A., Pozo-Cruz, J. del, Olivares, P. R., \& Gusi, N. (2012). Using wholebody vibration training in patients affected with common neurological diseases: a systematic literature review. The Journal of Alternative and Complementary Medicine, 18(1), 29-41.

Pronk, N. P., Katz, A. S., Lowry, M., \& Payfer, J. R. (2012). Peer Reviewed: Reducing Occupational Sitting Time and Improving Worker Health: The Take-a-Stand Project, 2011. Preventing Chronic Disease, 9.

Richter, R. R., \& Austin, T. M. (2012). Using MeSH (medical subject headings) to enhance PubMed search strategies for evidence-based practice in physical therapy. Physical Therapy, 92(1), 124.

Robertson, M., Amick, B. C., DeRango, K., Rooney, T., Bazzani, L., Harrist, R., \& Moore, A. (2009). The effects of an office ergonomics training and chair intervention on worker knowledge, behavior and musculoskeletal risk. Applied Ergonomics, 40(1), 124-135.

Robertson, M. M., Ciriello, V. M., \& Garabet, A. M. (2013). Office ergonomics training and a sit-stand workstation: Effects on musculoskeletal and visual symptoms and performance of office workers. Applied Ergonomics, 44(1), 73-85.

Robertson, M. M., \& O'Neill, M. J. (2003). Reducing musculoskeletal discomfort: effects of an office ergonomics workplace and training intervention. International Journal of Occupational Safety and Ergonomics, 9(4), 491-502. 
Shariat, A., TC Lam, E., Kargarfard, M., \& Danaee, M. (2015). The application of a feasible exercise training program in the office setting. Work: A Journal of Prevention. Assesment and Rehabilitation.

Sheahan, P. J., Diesbourg, T. L., \& Fischer, S. L. (2016). The effect of rest break schedule on acute low back pain development in pain and non-pain developers during seated work. Applied Ergonomics, 53, 64-70.

Sherman, K. J., Cherkin, D. C., Erro, J., Miglioretti, D. L., \& Deyo, R. A. (2005). Comparing yoga, exercise, and a self-care book for chronic low back pain: a randomized, controlled trial. Annals of Internal Medicine, 143(12), 849856.

Sherman, K. J., Cherkin, D. C., Wellman, R. D., Cook, A. J., Hawkes, R. J., Delaney, K., \& Deyo, R. A. (2011). A randomized trial comparing yoga, stretching, and a self-care book for chronic low back pain. Archives of Internal Medicine, 171(22), 2019-2026.

Siegmund, L. A., Barkley, J. E., Knapp, D., \& Peer, K. S. (2014). Acute effects of local vibration with biomechanical muscle stimulation on low-back flexibility and perceived stiffness. Athletic Training and Sports Health Care.

Sihawong, R., Janwantanakul, P., \& Jiamjarasrangsi, W. (2014). A prospective, cluster-randomized controlled trial of exercise program to prevent low back pain in office workers. European Spine Journal, 23(4), 786-793.

Sihawong, R., Janwantanakul, P., Sitthipornvorakul, E., \& Pensri, P. (2011). Exercise therapy for office workers with nonspecific neck pain: a systematic review. Journal of Manipulative and Physiological Therapeutics, 34(1), $62-71$.

Sullivan, A. B., Scheman, J., Venesy, D., \& Davin, S. (2012). The role of exercise and types of exercise in the rehabilitation of chronic pain: specific or nonspecific benefits. Current Pain and Headache Reports, 16(2), $153-161$.

Talebian, S., Hosseini, M., Bagheri, H., Olyaei, G. R., \& Reazasoltani, A. (2011). Trunk muscle fatigue in subjects with a history of low back pain and a group of healthy controls measured by similarity index. Journal of Back and Musculoskeletal Rehabilitation, 24(1), 17-22. http://doi.org/10.3233/BMR-2011-0270

Thorp, A. A., Healy, G. N., Winkler, E., Clark, B. K., Gardiner, P. A., Owen, N., \& Dunstan, D. W. (2012). Prolonged sedentary time and physical activity in workplace and non-work contexts: a cross-sectional study of office, customer service and call centre employees. Int J Behav Nutr Phys Act, 9(1), 128.

Van Middelkoop, M., Rubinstein, S. M., Verhagen, A. P., Ostelo, R. W., Koes, B. W., \& van Tulder, M. W. (2010). Exercise therapy for chronic nonspecific low-back pain. Best Practice \& Research Clinical Rheumatology, 24(2), 193-204. 